\title{
The importance of being scientifically cautious when criticizing the administration of vaccines: 'retracted' post truth
}

\author{
Amadou Barry ${ }^{1}$, Oscar A Bottasso ${ }^{2} \&$ Miguel H Vicco*,3 \\ ${ }^{1}$ Malaria Research \& Training Center, Faculty of Medicine, Pharmacy \& Dentistry, University of Sciences Techniques \& Technologies \\ of Bamako, Bamako, Mali \\ ${ }^{2}$ Instituto de Inmunología Clínica y Experimental de Rosario, Universidad Nacional de Rosario, Consejo Nacional de Investigaciones \\ Científicas y Técnicas, Rosario, Argentina \\ ${ }^{3}$ Facultad de Ciencias Médicas, Universidad Nacional del Litoral, Santa Fe, Argentina \\ *Author for correspondence: mvicco@santafe-conicet.gov.ar
}

\begin{abstract}
' ${ }$ it has been observed during one of the most important outbreaks of measles in California, a significant rate of children intentionally not-vaccinated against measles. Because of this, these children were at considerably higher risk of contracting the disease. If this trend continues growing, then measles could once again become an endemic disease"
\end{abstract}

First draft submitted: 18 May 2018; Accepted for publication: 17 October 2018; Published online: 7 December 2018

Keywords: antivaccines $\bullet$ post truth $\bullet$ preventive medicine $\bullet$ public health $\bullet$ vaccines

The sociologist Robert Merton postulated that science is a concept used in order to denote the set of methods used to verify the truth of knowledge. Science is to go beyond empiricism, and try to make real hypothetical concepts (or check their shortcomings). In this line, Pierre Louis introduced the numerical method to achieve scientific 'verification' of the medical practice - "As to different methods of treatment, it is possible for us to assure ourselves of the superiority of one or other [.. . ] by enquiring if under these circumstances, a greater number of individuals have been cured by one means than another. Here again it is necessary to count. And it is, in great part at least, because hitherto this method has been not at all, or rarely been employed, that the science of therapeutics is so uncertain" [1]. The principal objective pursued through this method was to avoid treatments whose efficacies were not really proven.

This method was improving over the years resulting in what we now know as evidence-based medicine. The aim of this methodology is to evaluate the quality of the evidence about the risks and benefits of the different intervention such as complementary studies in the assessment of a presumptive diagnosis or the treatment, provided by a healthcare professional [2]. One of the major results of evidence-based medicine is the development of systematic reviews and clinical guidelines leading to improvements of healthcare practice [3].

However, recently, we are experiencing a new thought era named 'post truth', defined as 'relating to or denoting circumstances in which objective facts are less influential in shaping public opinion than appeals to emotion and personal belief' [4]. Although post truth is not lying, but a relativization of truth, it can lead to disparage a truth, and so a lie can turn into a fact, confusion over reality [5]. This is happening within medicine and one of its worst impacts has been a positive feedback to the antivaccination movement.

The practice of vaccination dates back hundreds of years. It was in 1796 when Edward Jenner inoculated a young boy with cowpox inducing immunity to smallpox. During its employment there were several adverse events summarized by Aragón T et al. [6] in their systematic review. They concluded that life-threatening complications were at least three per million primary vaccinations. However, it is important to mention, as referred by the authors, that the study has its limitations regarding that a long time has passed since the last case of smallpox and diverse factors could have changed, such as the design of epidemiologic surveillance, diagnosis and treatment of vaccine complications, etc.

Finally, regarding this vaccine, there is other side effect that should be mentioned. As it was systematically administrated to the whole population, the global eradication of smallpox was achieved in 1979 [7]. This is

Future 8 Medicine 
important considering that the disease was responsible of 400,000 deaths per year in Europe during the 18th century, and 300-500 million deaths in the 20th century, most of them were babies and infants [8-10].

Since then vaccines are considered one of the greatest and effective health preventive interventions regarding morbidity and mortality due to infectious diseases. Furthermore, the Global Vaccine Alliance (GAVI) estimates that by the year $2020>23$ million of deaths due to infectious diseases such as hepatitis B, yellow fever, Haemophilus influenzae type $\mathrm{B}$, rubella, etc., would be averted by vaccination [11].

However, in the 1980s social movements started to criticize the use of vaccines. Several studies have analyzed the reasons why parents avoid immunization for their children, concluding that there is a wide range of factors that influence the decision, from social pressure, educational level or socioeconomic status, to perceptions of the safety of vaccines [12]. Regardless of the various factors, we have to do a mea culpa of the latter.

During the last few years we have been promoting the controversy of vaccine safety by articles that after their publication were re-worded or retracted due to misleading wording or several errors leading to false conclusions. Recently the title of the article 'Influenza vaccines seem to be modifying influenza into a dangerous dengue-like disease' published in the section Rapid Response of the British Medical Journal (BMJ) in March 2018, was modified in April to 'Influenza vaccines and dengue-like disease'. This was due to the misinterpretation induced by the title as it was described by Jon M Richfield [13].

Other examples include the article published in 1998 named 'Ileal-lymphoid-nodular hyperplasia, non-specific colitis, and pervasive developmental disorder in children', which was retracted due to false data [14]. In this article, Andrew Wakefield postulated that vaccine to protect against measles, mumps and rubella induced intestinal inflammation leading to the translocation of peptides into the bloodstream, and subsequently, to the brain promoting the development of autism. However, the study had numerous methodologies issues inducing to a false conclusion. Furthermore, nowadays several articles have showed that there is no link between this vaccine and autism [15,16].

Later the article named 'Measles-mumps-rubella vaccination timing and autism among young African-American boys: a reanalysis of $C D C$ data', was also retracted due to concerns in the validity of the methods [17]. Other example is the recently retracted article 'Systematic Assessment of Research on Autism Spectrum Disorder and Mercury Reveals Conflicts of Interest and the Need for Transparency in Autism Research' [18] due to concerns about the validity of the conclusions.

Despite that these articles were properly corrected or withdrawn, the false conclusions have been already promoting a positive feedback to the antivaccination movement or integrative and holistic physicians $[19,20]$ with a negative impact on the community welfare.

The rising concerns about vaccine safety due to the antivaccine statements are affecting the manufacturing development strategy of the vaccine, and the immunization coverage as healthcare professionals and individuals are refusing vaccine usage [21]. In this line, it has been observed during one of the most important outbreaks of measles in California, a significant rate of children intentionally not-vaccinated against measles. Because of this, these children were at considerably higher risk of contracting the disease. If this trend continues growing, then measles could once again become an endemic disease [22].

In addition, the same concerns must be considered by the vaccine manufacturing companies. As referred by Poland G et al. [23] the design of new vaccines, particularly in the framework of personalized medicine, would require an important educational effort to mitigate the false assumptions attributed to vaccines by the antivaccines movements.

Therefore, reversing this situation is necessary to promote an optimal communication to the society regarding the vaccine's benefit risk balance. When we perform science, we are trying to increase our level of justified beliefs. We are very conscious of the warning raised by Bertrand Russel that "the extent to which beliefs are based on evidence is much less than believers suppose". Bringing to discussion the important role of vaccines in promoting society welfare should be done with the most serious evidence possible, and that must be our aim.

Financial \& competing interest's disclosure

The authors have no relevant affiliations or financial involvement with any organization or entity with a financial interest in or financial conflict with the subject matter or materials discussed in the manuscript apart from those disclosed. This includes employment, consultancies, honoraria, stock ownership or options, expert testimony, grants or patents received or pending, or royalties.

No writing assistance was utilized in the production of this manuscript. 


\section{References}

1. Louis A. Resume of a clinical course or an inquiry into general facts. In: An essay on clinical instruction. Translated by Peter Martin. Highley Publisher, London, UK, 26-27 (1834). https://archive.org/details/b22384285/page/n0

2. Elstein AS. On the origins and development of evidence-based medicine and medical decision making. Inflamm. Res. 53(Suppl 2), S184-S189 (2004).

3. Sheridan DJ, Julian DG. Achievements and limitations of evidence-based medicine. J. Am. Coll. Cardiol. 12;68(2), 204-213 (2016).

4. Oxford dictionaries. https://en.oxforddictionaries.com/definition/post-truth

5. Zarzalejos JA. Communication journalism and fact-checking. UNO Magazine 24, 11-13 (2017).

6. Aragón TJ, Ulrich S, Fernyak S, Rutherford GW. Risks of serious complications and death from smallpox vaccination: a systematic review of the United States experience, 1963-1968. BMC Public Health 11(3), 26 (2003).

7. Bhattacharya S. Reflections on the eradication of smallpox. Lancet 8;375(9726), 1602-1603 (2010).

8. Riedel S. Edward Jenner and the history of smallpox and vaccination. Proc. (Bayl. Univ. Med. Cent.) 18(1), 21-25 (2005).

9. Riedel S. Smallpox and biological warfare: a disease revisited. Proc. (Bayl. Univ. Med. Cent.) 18(1), 13-20 (2005).

10. Koplan JP, Foster SO. Smallpox: clinical types, causes of death, and treatment. J. Infect. Dis. 140(3), 440-441 (1979).

11. Lee LA, Franzel L, Atwell J et al. The estimated mortality impact of vaccinations forecast to be administered during 2011-2020 in 73 countries supported by the GAVI Alliance. Vaccine 18(31 Suppl. 2), B61-72 (2013).

12. Dubé E, Vivion M, MacDonald NE. Vaccine hesitancy vaccine refusal and the anti-vaccine movement: influence, impact and implications. Expert Rev. Vaccines 14(1), 99-117 (2015).

13. Richfield J. Re: influenza vaccines seem to be modifying influenza into a dangerous dengue-like disease (MEPs devise strategy to tackle vaccine hesitancy among public). Rapid response section. BMJ 360, k1378 (2018).

14. Wakefield AJ, Murch SH, Anthony A et al. Ileal-lymphoid-nodular hyperplasia, non-specific colitis, and pervasive developmental disorder in children. Lancet 28;351(9103), 637-641 (1998). RETRACTED [Lancet. 6;375(9713):445 (2010)].

15. Madsen KM, Hviid A, Vestergaard $\mathrm{M}$ et al. A population-based study of measles, mumps, and rubella vaccination and autism. N. Engl. J. Med. 7;347(19), 1477-1482 (2002).

16. Gerber JS, Offit PA. Vaccines and autism: a tale of shifting hypotheses. Clin. Infect. Dis. 48(4), 456-461 (2009).

17. Hooker BS. Measles-mumps-rubella vaccination timing and autism among young African American boys: a reanalysis of CDC data. Transl. Neurodegener. 8(3), 16 (2014). RETRACTED [Transl. Neurodegener. 3;3, 22 (2014)].

18. Kern JK, Geier DA, Deth RC et al. Systematic assessment of research on autism spectrum disorder (ASD) and mercury reveals conflicts of interest and the need for transparency in autism research. Sci. Eng. Ethics 23(6), 1691-1718 (2017). RETRACTED [Sci. Eng. Ethics. 23(6), 1689-1690 (2017)].

19. Tomeny TS, Vargo CJ, El-Toukhy S. Geographic and demographic correlates of autism-related anti-vaccine beliefs on Twitter, $2009-15$. Soc. Sci. Med. 191, 168-175 (2017).

20. Buehning LJ, Peddecord KM. Vaccination attitudes and practices of integrative medicine physicians. Altern. Ther. Health Med. 23(1), 46-54 (2017).

21. Poland GA, Jacobson RM. Understanding those who do not understand: a brief review of the anti-vaccine movement. Vaccine 21;19(17-19), 2440-2445 (2001).

22. Sugerman DE, Barskey AE, Delea MG et al. Measles outbreak in a highly vaccinated population, San Diego, 2008: role of the intentionally undervaccinated. Pediatrics 125(4), 747-755 (2010).

23. Poland GA, Murray D, Bonilla-Guerrero R. New vaccine development. BMJ 1; 324(7349), 1315-1319 (2002). 
